\title{
Evaluation of the CPTEC/AGCM wind forecasts during the hurricane Catarina occurrence
}

\author{
A. F. Santos ${ }^{1}$, A. M. Mendonça ${ }^{1}$, J. P. Bonatti ${ }^{1}$, J. G. Z. de Mattos $^{1}$, P. Y. Kubota ${ }^{1}$, S. R. Freitas ${ }^{1}$, M. A. F. Silva Dias ${ }^{1}$, \\ E. Ramirez ${ }^{2}$, and R. Camayo ${ }^{3}$ \\ ${ }^{1}$ Center for Weather Prediction and Climate Studies, Cachoeira Paulista, São Paulo, Brazil \\ ${ }^{2}$ Institute of Astronomy, Geophysics and Atmosferic Science, University of Sao Paulo, Sao Paulo, Brazil \\ ${ }^{3}$ Oceanographic Institute, University of São Paulo, São Paulo, Brazil
}

Received: 15 June 2007 - Revised: 31 January 2008 - Accepted: 15 February 2008 - Published: 7 May 2008

\begin{abstract}
In March 2004 occurred the first hurricane registered at South Atlantic Ocean. The system named Catarina begun as an extratropical cyclone and remained quasistationary some days over the South Atlantic Ocean. The system displaced westward, acquiring characteristics of a hurricane and hit the Brazilian State of Santa Catarina (SC) between the 27 and the 28 March, causing destruction and deaths. The objective of this paper is to evaluate the Center for Weather Prediction and Climate Studies, Atmospheric Global Circulation Model (CPTEC/AGCM) forecast performance of some synoptic patterns associated with Catarina. The surface wind and reduced Sea Level Pressure (SLP) were examined. Moreover, the implementation of 10-m wind forecast (V10m) was evaluated. This variable was not available in the CPTEC/AGCM during the Catarina occurrence and in this study it was compared with the wind at first sigma-level of the AGCM. The CPTEC-Eta reanalyses were used to comparisons. According to reanalyses, more intense winds were observed in northeast, south and southwest edges of the cyclone. The system was not predicted by the CPTEC/AGCM forecasts longer than $24 \mathrm{~h}$, then the analyses were carried out only for $24 \mathrm{~h}$ forecasts. In general, the first sigma-level wind forecasts underestimated the wind magnitude and the cyclone intensity. However, the Catarina formation and its displacement southeastward between the 20 and the 21 March were well represented by the model. The CPTEC/AGCM presents deficiencies to predict the system intensity, but in short-range forecasts it was possible to predict the system formation and its atypical trajectory. The wind results from the new implementation did not exhibit better performance compared with the wind at first sigma-level. These results will be better investigated in the future.
\end{abstract}

Correspondence to: A. F. Santos

(ariane@cptec.inpe.br)

\section{Introduction}

In March 2004 it was registered the first occurrence of a hurricane over the South Atlantic Ocean since the advent of the Meteorological satellite era. The hurricane named Catarina, started as an extratropical cyclone off the Brazilian coast and remained quasi-stationary during some days over the South Atlantic. Later, the system displaced westward, acquiring characteristics of a hurricane and hit the Brazilian States of Santa Catarina (SC) and northern of Rio Grande do Sul (RS) between the 27 and the 28 March. Its name is a reference to the main State affected by the system (SC) where it caused destruction and deaths. According to National Hurricane Center (NHC) at Miami, Catarina reached category I hurricane on the Saffir-Simpson scale. As shown in Pezza and Simmonds (2005), although the system has formed over near-average water temperatures, Catarina underwent Tropical Transition (TT) under low vertical wind shear two days after its genesis. The vertical structure presented anticyclonic relative vorticity and a small warm core embedded in a cold area in upper levels. Bonatti et al. (2006) analyzed the hurricane Catarina through computing vorticity conservation, thermodynamic energy and specific humidity using National Centers for Environmental Prediction (NCEP) analysis. The results showed that the main term responsible for the westward propagation was the relative vorticity stretching followed by the planetary vorticity stretching. They also performed simulations based on the Center for Weather Prediction and Climate Research, Atmospheric Global Circulation Model (CPTEC/AGCM) with operational and high resolution. The main characteristics associated with Catarina were well predicted. However, the changes in the resolution did not produce improvements in the Catarina intensity forecast, on the other hand, the higher resolution contributed to produce a good representation of the rain field associated with Catarina due the best representation of topography.

Published by Copernicus Publications on behalf of the European Geosciences Union. 
The main goal of this study is to evaluate the surface wind forecasts of the CPTEC/AGCM model in its operational version during the Catarina occurrence. Moreover, the implementation of $10-\mathrm{m}$ wind diagnosis (V10m) in CPTEC/AGCM model is also evaluated, that it was not available in the model in that period.

\section{Model description}

The CPTEC/AGCM has its origin in that model used for medium-range weather forecast at NCEP in 1985 and modified by the Center for Ocean-Land-Atmosphere Studies (COLA) in the 80's and 90's (Bonatti, 1996). The CPTEC adopted the version 1.7 from COLA, with romboidal truncation. It was introduced the triangular truncation and modifications and the model was adapted CPTEC necessities. Currently, the CPTEC/AGCM version used to produce operational weather prediction has a T213L42 resolution, corresponding to about $63 \mathrm{~km}$ in the region of Catarina occurrence (Bonatti et al., 2006).

The CPTEC/AGCM is based on the spectral solution of primitive dynamic equations in the divergence and vorticity form, virtual temperature, specific humidity and surface pressure logarithm and inclusion of sub-grid process through parameterizations. The main physical processes parameterized in the model are:

- deep cumulus convection Grell (1988);

- shallow cumulus (Tiedtke, 1983);

- large scale convection (NMC, 1988).

- Simplified Simple Biosphere model over the land (SSiB) (Xue et al., 1991);

- aerodynamic bulk scheme over the sea (Sato et al., 1989);

- Planetary Boundary Layer (PBL) (Mellor and Yamada, 1982);

- radiative fluxes: short wave (Lacis and Hansen, 1974), modified by Davies (1982); long wave (Harshvardhan et al., 1987).

More details about the CPTEC/AGCM can be found in Kinter III (1997).

\section{Data}

The initial conditions used to integrate the CPTEC/AGCM were obtained from NCEP at the T126L28 resolution. The forecasts were generated integrating the model up to 3 days and saving results each 3 integration hours, after the initial model times of 00:00 UTC and 12:00 UTC, from the 19
March 2004 to the 29 March 2004. A total of 22 model integrations were generated. The Sea Level Pressure (SLP), first sigma-level wind (Vves, approximately $40 \mathrm{~m}$ over the surface) and V10m fields were evaluated in this study.

The forecast verifications were made using the corresponding fields generated by the mesoscale CPTEC-Eta model reanalyses (Aravéquia et al., 2008). The reanalyses were developed using the Regional Physical-Space Analysis System (RPSAS). The RPSAS is formed by the operational mesoscale Eta model and the CPTEC data assimilation scheme named Physical-Space Analysis System (PSAS). The PSAS was developed at the Global Modeling and Assimilation Office/National Aeronautics and Space Administration (GMAO/NASA) and it was implemented at CPTEC in 2003. The CPTEC-Eta model version used to produce the reanalyses has a $40 \mathrm{~km}$ horizontal resolution and 38 vertical levels. More details about the CPTEC-Eta model can be found in Black (1994). The reanalyses are available for January 2000 to December 2004.

The wind fields derived from QuikSCAT were used to evaluate the reanalyses quality. The QuikSCAT is a wind map at 10-m over the sea and it is obtained from polar orbit satellite as well as processed by National Oceanic and Atmospheric Administration (NOAA). These data are available at near real-time for weather forecasting agencies around the world.

Wind data from automatic meteorological stations over land in SC provided for the company of farming research and agricultural extension (in Portuguese Empresa de Pesquisa Agropecuária e Extensão Rural de SC - Epagri) were used to forecast verifications. Three stations were used to comparisons, as follows: Siderópolis $\left(28^{\circ} 35^{\prime} 52^{\prime \prime} \mathrm{S} / 49^{\circ} 25^{\prime} 28^{\prime \prime} \mathrm{W}\right)$, Campos Novos $\left(27^{\circ} 24^{\prime} 06^{\prime \prime} \mathrm{S} / 51^{\circ} 13^{\prime} 30^{\prime \prime} \mathrm{W}\right)$ and São Francisco do Sul $\left(26^{\circ} 14^{\prime} 36^{\prime \prime} \mathrm{S} / 48^{\circ} 38^{\prime} 17^{\prime \prime} \mathrm{W}\right)$. Amongst all available stations, these stations were the ones which presented more intense winds in the period of Catarina occurrence.

\section{Methodology}

In the version implemented at CPTEC/AGCM, the V10m diagnosis is computed based on the surface fluxes and the Monin-Obukhov similarity theory (Arya, 2001), as follows bellow:

$$
\left.\mathrm{V} 10 \mathrm{~m}=\left(\frac{u_{*}^{2}}{2 * b * R_{i b}}\right)^{2 * 1-\frac{1 / 2}{1+2 * c_{m} * b * a^{2} * \sqrt{\left(z / z_{o} *\left|R_{i b}\right|\right)}}}\right)^{1}
$$


to $R_{i}<0$, and

$$
\mathrm{V} 10 \mathrm{~m}=\left(\frac{u_{*}^{2} * f h}{a^{2} * 1-\frac{\sqrt{1+d * R_{i}}}{\sqrt{1+d * R_{i}}+2 * b * R_{i}}}\right)^{1 / 2}
$$

to $R_{i}>0$, where $f h$ is a calibration parameter, $a^{2}=$ $k^{2} /\left(\ln \left(z / z_{o}\right)^{2}\right)$ and with $k$ von Karmann constant $(=0.35)$, $z$ the first sigma-level height and $z_{0}$ the roughness length. $b=5 ; c_{m}=7.5, u_{*}$ is the friction velocity and $R_{i b}$ is the bulk Richardson number given by:

$$
R_{i b}=\frac{g z \Delta \theta}{\frac{1}{2}\left(\bar{\theta}(z)+\bar{\theta}_{s}\right) \bar{U}^{2}}
$$

where $g$ is the gravity acceleration, $\Delta \theta=\bar{\theta}(z)-\bar{\theta} S$, where $\bar{\theta}$ is the mean potential temperature and suffix $S$ represents the variable at surface, and $\bar{U}=\left(\overline{u(z)}^{2}+\overline{v(z)}^{2}\right)^{1 / 2}$ is the mean wind at first sigma-level.

The Catarina evolution was analyzed through GOES-12 satellite imagery, SLP and wind fields from Eta reanalysis. These fields were also used to AGCM forecast verifications. Some grid points from reanalysis and CPTEC/AGCM model, near to meteorological stations in $\mathrm{SC}$ were selected to verification.

The CPTEC/AGCM forecast verifications were performed computing statistical indexes to measure the model ability during Catarina occurrence. The mean systematic error or bias and the Mean Absolute Error (MAE) were computed using Siderópolis, Campos Novos and São Francisco do Sul observations and corresponding grid point forecasts during the 19-31 March 2004.

The bias can be estimated as presented in Jolliffe and Stephenson (2003):

$$
\text { bias }=\frac{1}{N} \sum_{i=1}^{N}(P-O),
$$

where $N$ is the sample size, $P$ is the forecast value and $O$ is the observed value at day $i$.

The bias may be an inadequate measure of skill since negative errors can compensate positive errors (Wilks, 1995). A way to avoid the compensation of positive and negative forecast errors is to compute the MAE, that it is the mean absolute values of each forecast error, as follows:

$$
\mathrm{MAE}=\frac{1}{N} \sum_{i=1}^{N}|P-O| .
$$

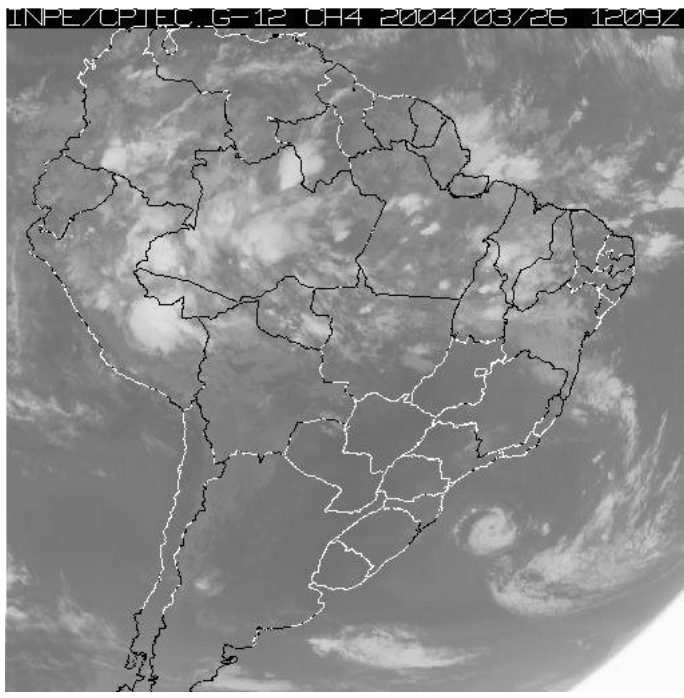

(a)

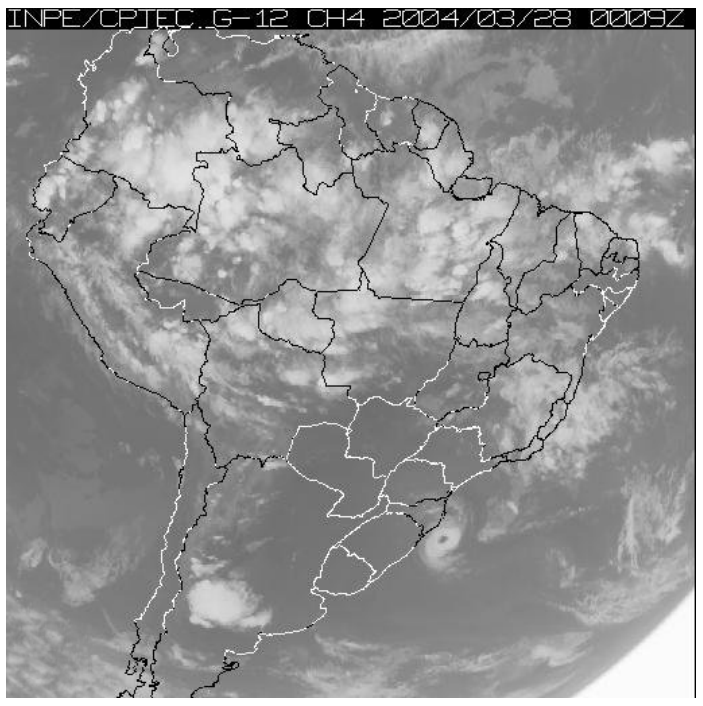

(b)

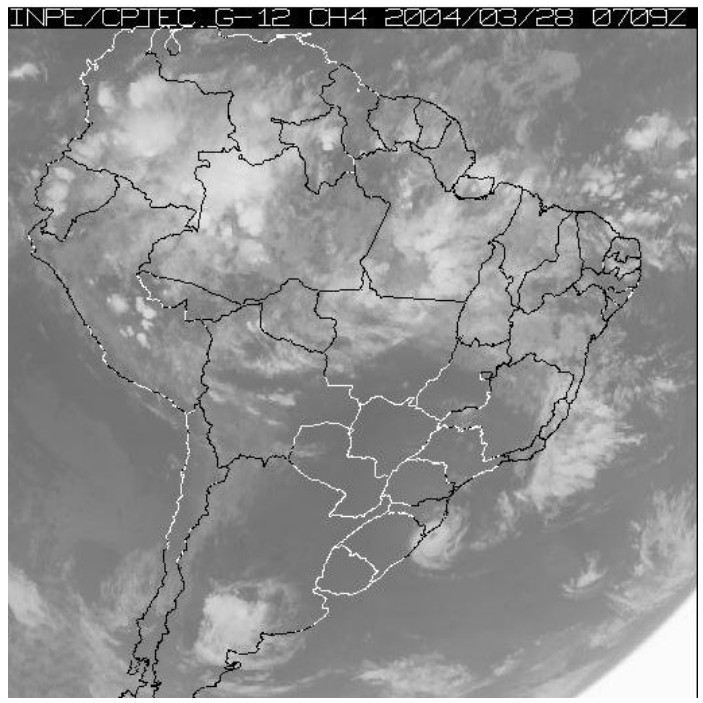

(c)

Fig. 1. GOES-12 satellite imagery to: (a) 03/26/2004 at 12:09 UTC; (b) 03/28/2004 at 00:09 UTC; (c) 03/28/2004 at 07:09 UTC. 


\section{Results}

\subsection{Catarina life cycle}

The hurricane Catarina was originated from an extratropical cyclone in a semi-stationary frontal system over the South Atlantic Ocean. On the 20 March, near the Southeastern Brazilian coast it was verified a cyclogenesis that remained some days over the ocean up to the 23 March almost without displacement, it was increasing the intensity (figure not shown). Over ocean it was observed an inverted comma cloud convection up to the 24 March (figure not shown). On the 26 March at 12:00 UTC (Fig. 1a), the system started the westward trajectory increasing the convection and developing the typical eye characterized by cloud absence in the core of the cyclone. The Catarina was localized in SC and RS coast, hitting the land on the 27 March between 21:00 UTC (figure not shown) and the 28 March at 00:00 UTC (Fig. 1b). The system started to decay on the 28 March at 07:00 UTC (Fig. 1c), but cloudiness yet had been seen until the 29 March (figure not shown).

From SLP and V10m reanalyses fields on the 20 March it was verified a cyclogenesis over the Atlantic Ocean, near Southeastern Region and it displaced southeastward remained semi-stationary until the 23 March (Fig. 2a). In this day, it was observed an increasing of pressure gradient in southeast cyclone. The pressure center was between $1010 \mathrm{hPa}$ and $1008 \mathrm{hPa}$ during this day. The Catarina displaced northeastward slowly on 24 March (figure not shown). On the $27 \mathrm{March}$, the pressure gradient decreased over the ocean but it remained intense over the land (Fig. 2e). The cyclone core remained over the South Atlantic Ocean during the 27 March reaching the land only on the 28 March (figure not shown) when the system intensity started decreasing after 12:00 UTC. The more intense winds were observed mainly northeast, south and southeast cyclone, with magnitude around 10 to $12 \mathrm{~ms}^{-1}$. Intense winds in southern SC and northern RS were observed after the cyclone decreasing.

\subsection{QuikSCAT fields X Reanalysis}

In the QuikSCAT fields the winds were relatively more intense than observed in reanalysis in northern system and similar values in southern system between the 26 March (Fig. 3a) and the 28 March (Fig. 3d). On the 26 March, the wind magnitude in northern of the Catarina varied from $15 \mathrm{~ms}^{-1}$ to $20 \mathrm{~ms}^{-1}$ and in south and east edges of the system the winds varied from $10 \mathrm{~ms}^{-1}$ to $12 \mathrm{~ms}^{-1}$ during ascend trajectory of the satellite. We could not identify the Catarina during the ascending passage of the satellite on the 27 March (Fig. 3b) due to satellite imperfection covering. On the other hand, we verified a tong of intense winds (from $7 \mathrm{~ms}^{-1}$ to $20 \mathrm{~ms}^{-1}$ ) comes from south RS $\left(30^{\circ}-35^{\circ} \mathrm{S} / 45^{\circ}-50^{\circ} \mathrm{W}\right)$ to coast SC. The reanalysis indicated $10 \mathrm{~ms}^{-1}$ wind weaker than QuikSCAT. In the descending passage of the satellite (Fig. 3c) there was a change in the wind direction in coast RS and SC that it reached the land almost perpendicularly. The QuikSCAT was in agreement in magnitude with reanalysis on the 28 March (in ascending passage) when wind near RS and SC coast reached approximately $12 \mathrm{~ms}^{-1}$.

\subsection{CPTEC/AGCM forecasts}

The hurricane Catarina formation and evolution were well represented only up to 24-hour forecasts, so we analyzed the system using only short range forecasts (24-h).

In general, there was an underestimation of the cyclone by the CPTEC/AGCM forecasts. The forecasts indicated the central pressure expanded horizontally and less intense. We observed the pressure gradient in southeast cyclone weaker than in the reanalyses. The cyclogenesis that originated the Catarina was well predicted by forecasts started on the 20 March at 00:00 UTC and 12:00 UTC. However, between the 24th and the 25 March (Fig. 4c and 4e), the cyclone was not well performed by forecasts valid to 00:00 UTC. In the runs valid to 12:00 UTC, the cyclone decreased on the 23 March (Fig. 4b) and remained configured from the 24 March (Fig. 4d) to the 27 March (Fig. 4f, $\mathrm{h}$ and j). On the $27 \mathrm{March}$ (Fig. 4i) the pressure gradient between the land near SC and the ocean was more intense at 00:00 UTC forecasts. On the 28 March at 00:00 UTC (Fig. 4k) when the system showed relative increase in intensity and reached the land, the model indicated decrease of the system and underestimation of the center of the pressure. The dissipation of the system was predicted on the 28 March at 12:00 UTC (Fig. 4l), as observed at the reanalyses field.

In the Fig. 4 it is also presented the first sigma-level wind fields. The most intense wind regions in the edges of the cyclone were well predicted by the model although the intensity has been underestimated when compared with reanalyses. The most intense winds were observed at 00:00 UTC forecasts agreeing to intense pressure gradient. On the 27 March (Fig. 4i), the intense pressure gradient favored intense winds. On the other hand, on the 28 March at 00:00 UTC (Fig. 4k), the model indicated a decrease in the winds that reached SC and northern RS.

The V10m field evaluation indicated that there are deficiencies in its implementation. The forecasted field was very underestimated, mainly over ocean. During the period of intense activity of the hurricane Catarina (Fig. 5), the forecasts showed wind magnitude lower than $4 \mathrm{~ms}^{-1}$ in all area, very underestimated if compared with the first sigma-level wind fields. This result should be associated to the calibration of the parameters used in the methodology to compute V10m. There are a necessity to verify a correct adjustment for these parameters.

The forecast verifications of some meteorological stations in SC (Table 1) showed that the observed wind was well represented by the forecasts in some days. The positive and negative bias in the forecasts at 00:00 UTC and a highest 
a)

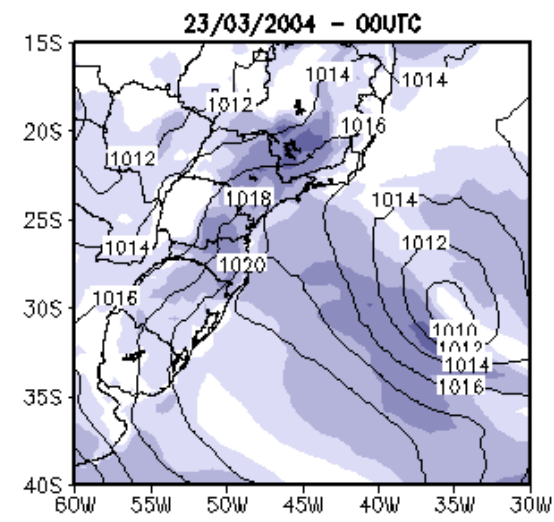

c)

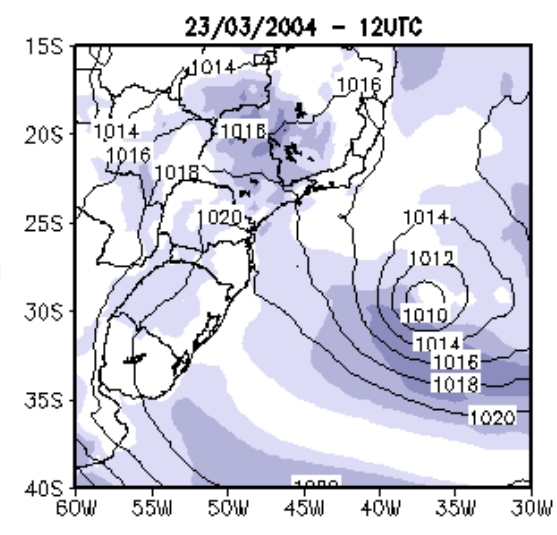

e)

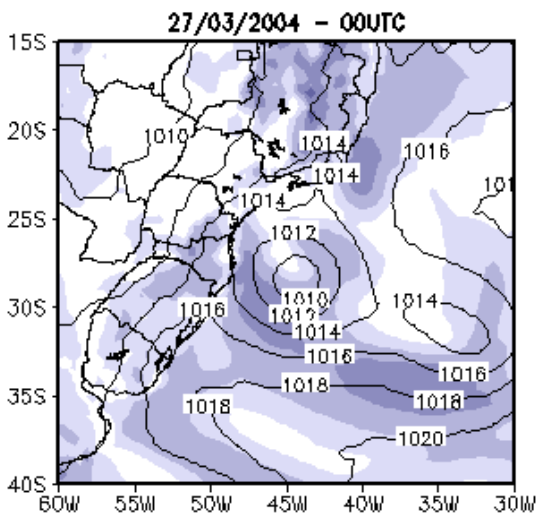

g)

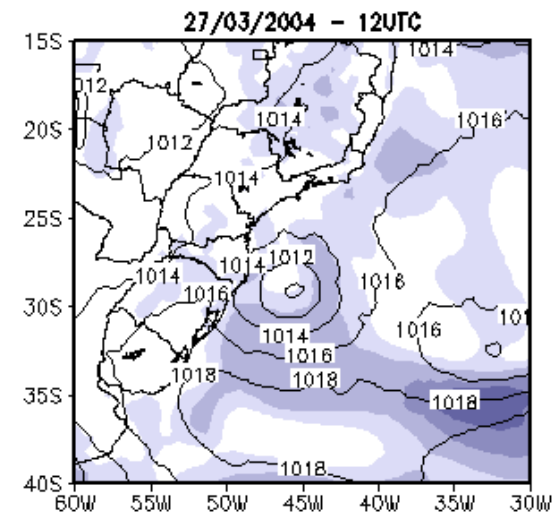

b)
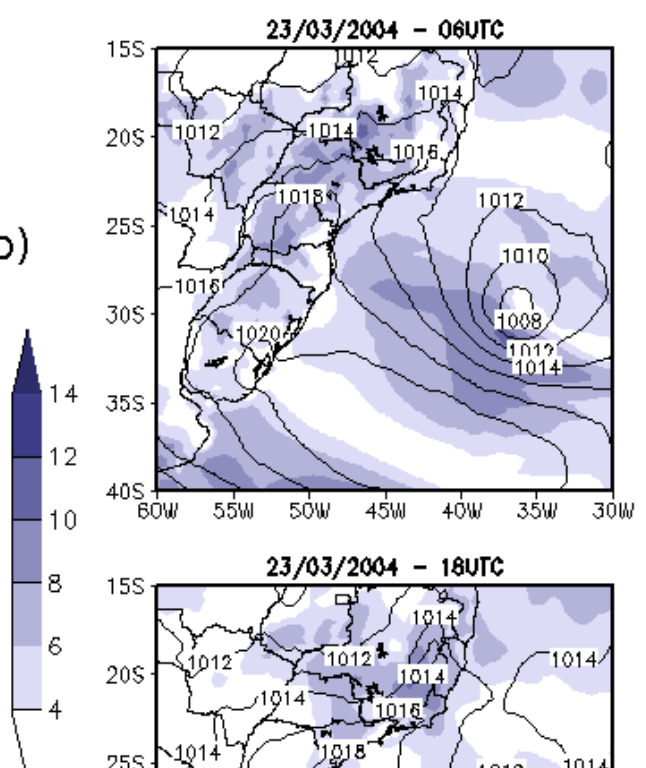

d)
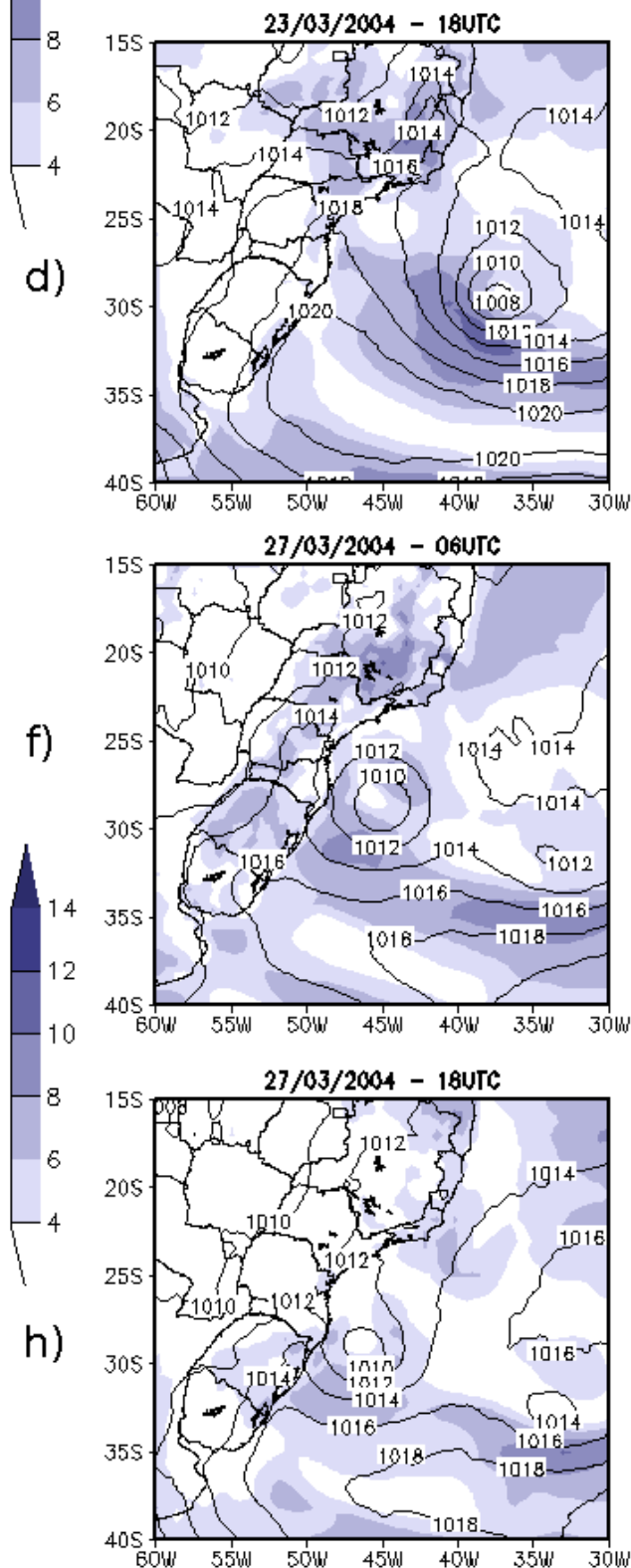

Fig. 2. SLP fields (hPa, solid lines) and V10m (in $\mathrm{ms}^{-1}$, shading) from Eta reanalyses on: (a) 03/23/2004 at 00:00 UTC, (b) 03/23/2004 at 06:00 UTC, (c) 03/23/2004 at 12:00 UTC, (d) 03/23/2004 at 18:00 UTC, (e) 03/27/2004 at 00:00 UTC, (f) 03/27/2004 at 06:00 UTC, (g) 03/27/2004 at 12:00 UTC, (h) 03/27/2004 at 18:00 UTC. 


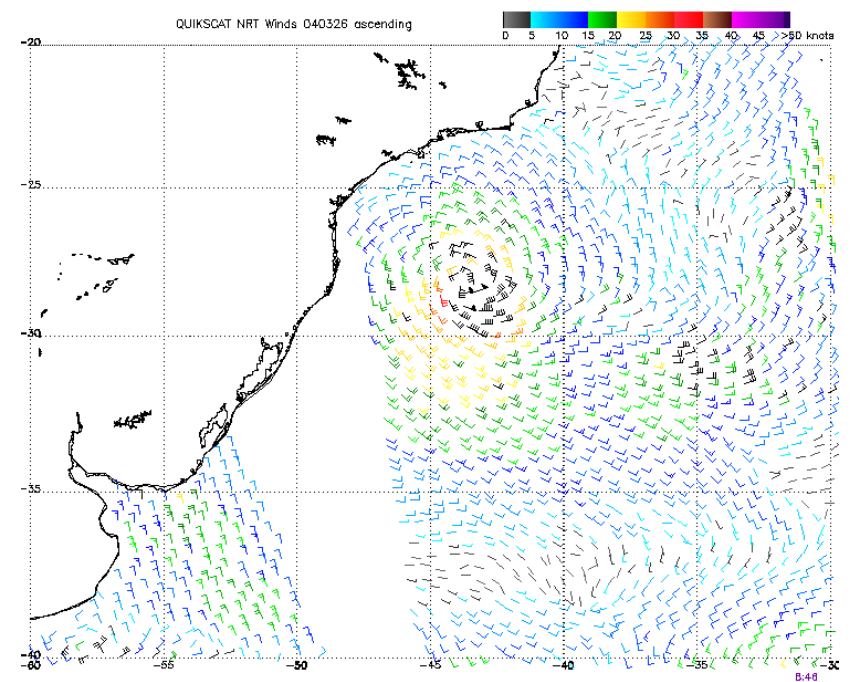

a)

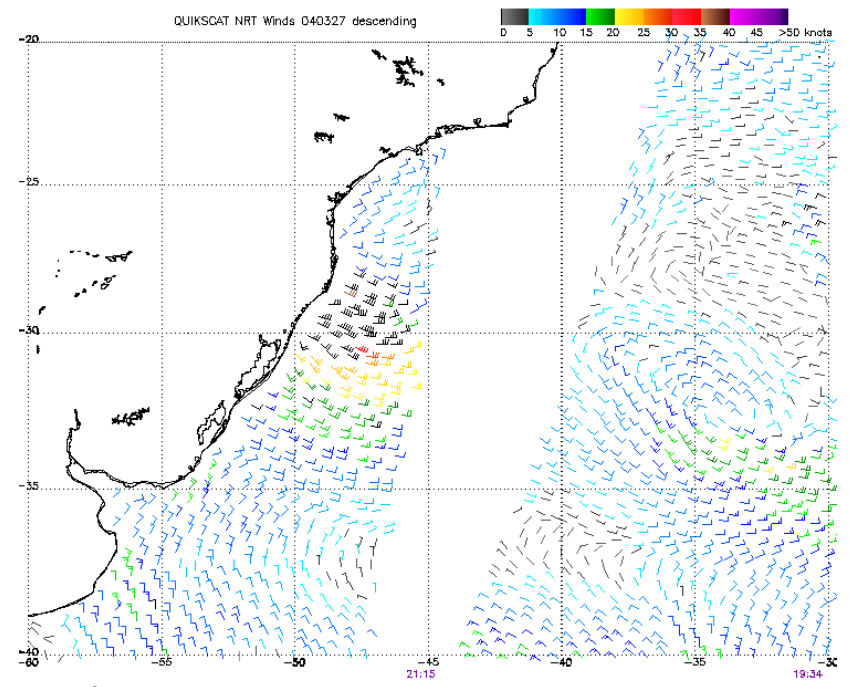

c)

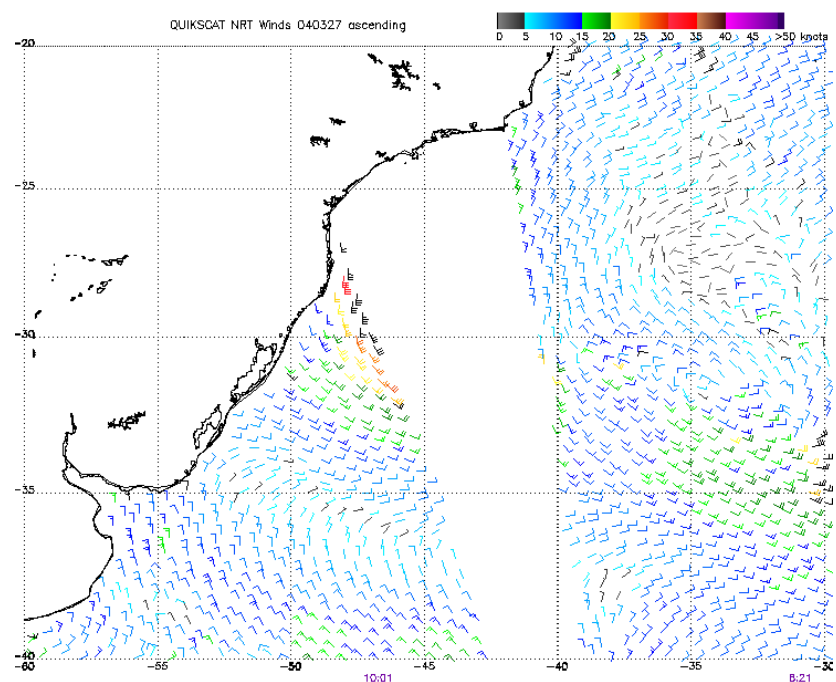

b)

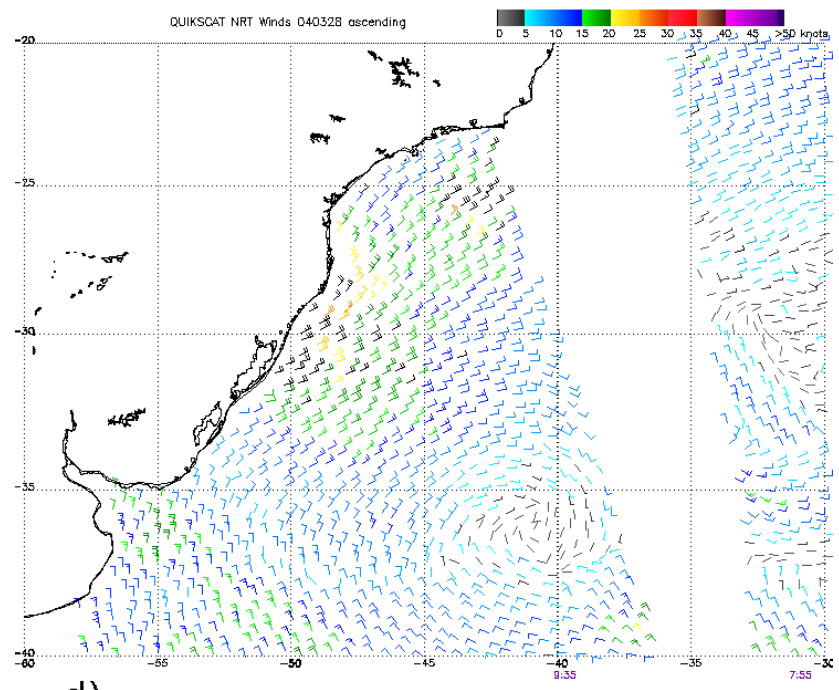

d)

Fig. 3. QuikSCAT fields during: (a) 03/26, ascending passage; (b) 03/27, ascending passage; (c) 03/27, descending passage; (d) 03/28, ascending passage. Wind in knots and black barbs indicate possible rain contamination.

Team (2007)

negative bias at 12:00 UTC forecasts were verified. In this case, the model produced different forecasts after the different initial conditions, it possibly associated with amount of data available to produce the analyses. The bias showed that the model suggest wind speed underestimation in both runs. Although Vves has underestimated the real wind, it showed better performance compared with the $\mathrm{V} 10 \mathrm{~m}$. The reanalysis underestimated the wind in both initial runs. At 00:00 UTC, the errors are small and in two stations the reanalysis overestimated the wind speed. The MAE indicated that highest errors are verified at 12:00 UTC for both CPTEC/AGCM forecasts and reanalysis. For 24h-forecasts started at 00:00 UTC, it is observed that Vves errors are smaller than V10m errors.
Although the CPTEC/AGCM has relatively high resolution, it is not enough for resolving a hurricane. Bonatti et al. (2006) using simulation experiments with the CPTEC/AGCM, with different resolutions, observed that the high resolution of the model did not improve better representation of the hurricane Catarina intensity and wind field associated. There are a necessity to use mesoscale models and better cloud parameterization to predict with more accuracy and longer lead times extreme events like Catarina. 
(a)

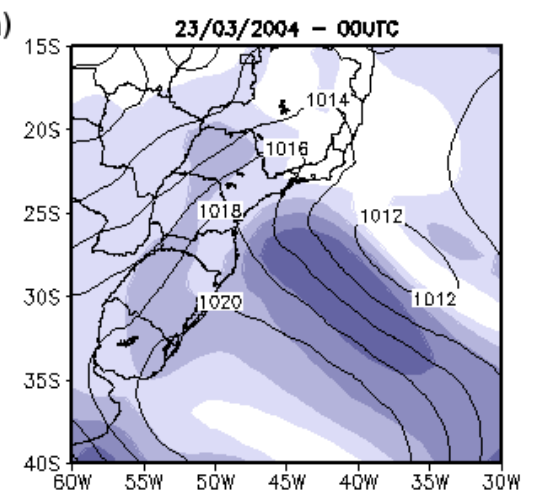

(c)

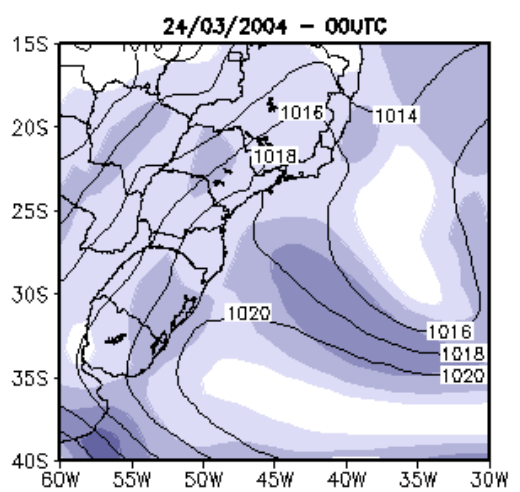

(e)

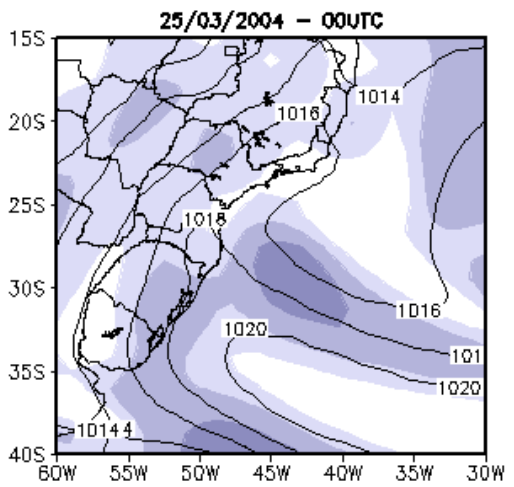

(g)

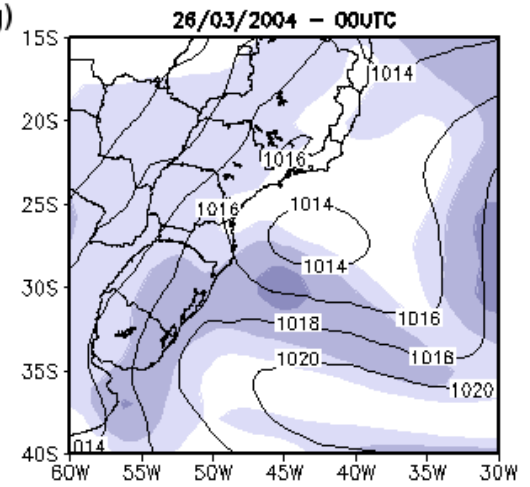

(b)

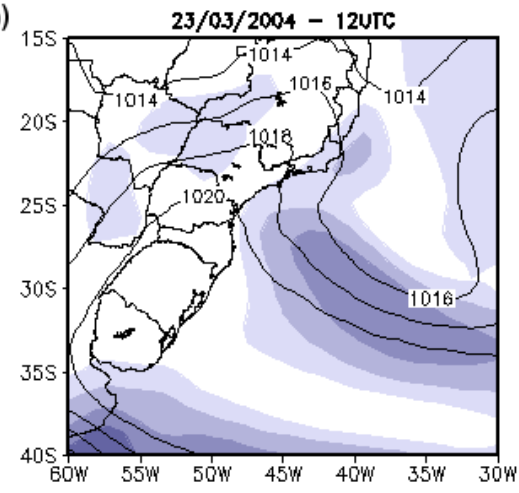

(d)

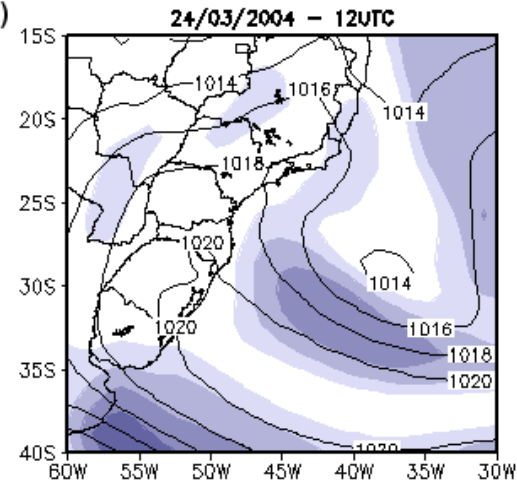

(f)

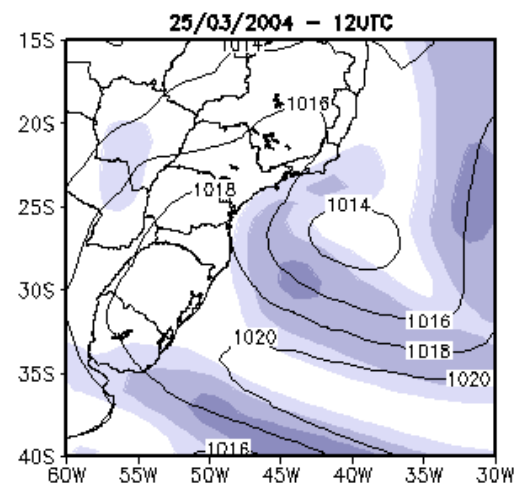

(h)

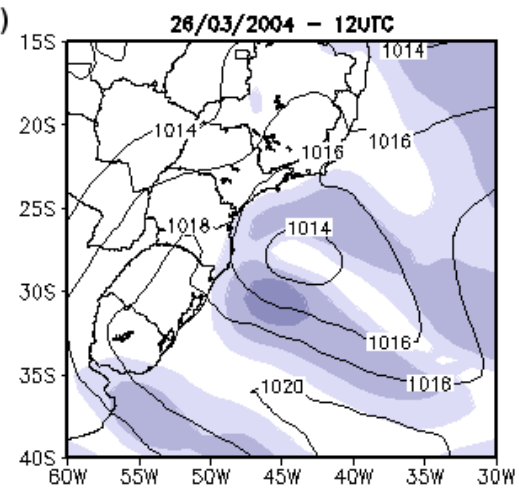

Fig. 4. SLP (solid lines, in $\mathrm{hPa}$ ) and wind at first sigma level (shading in $\mathrm{ms}^{-1}$ ) 24-h CPTEC/AGCM forecasts valid for: (a) 03/23 at 00:00 UTC, (b) 03/23 at 12:00 UTC, (c) 03/24 at 00:00 UTC, (d) 03/24 at 12:00 UTC, (e) 03/25 at 00:00 UTC, (f) 03/25 at 12:00 UTC, (g) 03/26 at 00:00 UTC, (h) 03/26 at 12:00 UTC, (i) 03/27 at 00:00 UTC, (j) 03/27 at 12:00 UTC, (k) 03/28 at 00:00 UTC, (l) 03/28 at 12:00 UTC. 
(i)

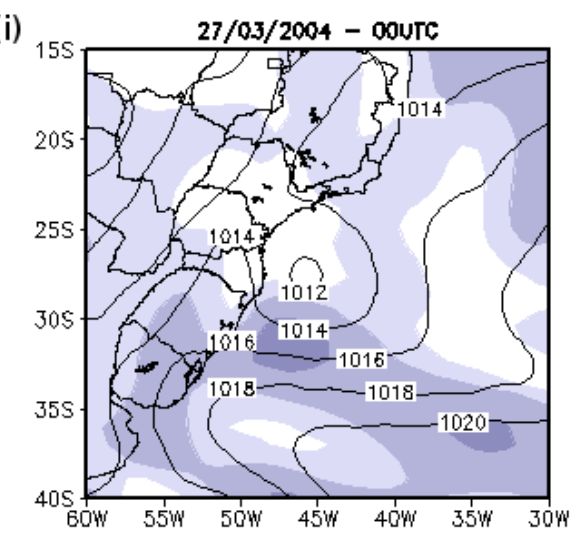

(k)

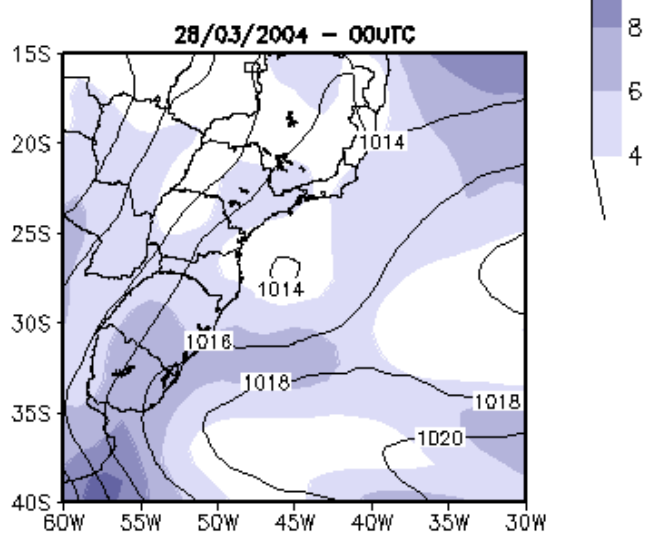

(j)

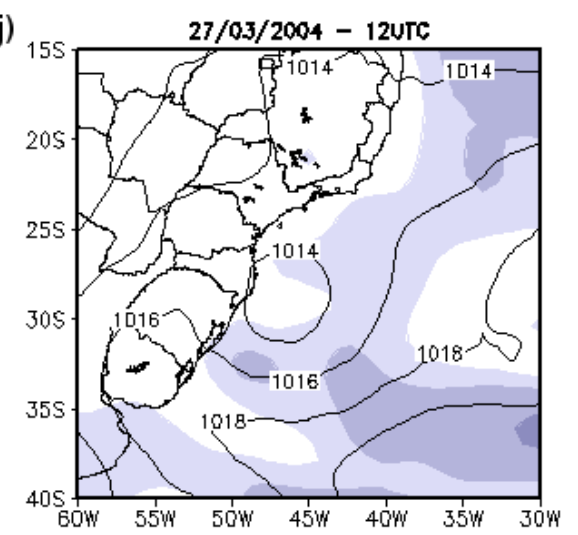

(I)

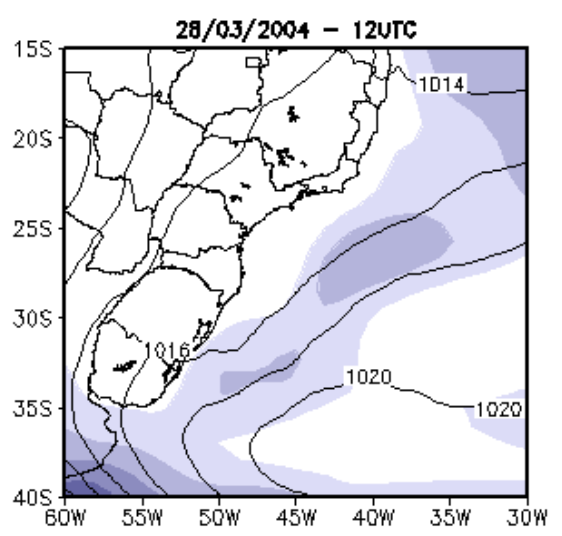

Fig. 4. Continued.

Table 1. Statistical index MAE $\left(\mathrm{ms}^{-1}\right)$ and bias $\left(\mathrm{ms}^{-1}\right)$ to the 19-31 March 2004 computed to CPTEC/AGCM forecasts and reanalyses in the meteorological stations of Siderópolis (Sid), Campos Novos (CNov) and São Francisco do Sul (SFco).

\begin{tabular}{lrrrrrr}
\hline AGCM & \multicolumn{3}{c}{ V10m } & \multicolumn{3}{c}{ Vves } \\
\hline Index & Sid. & C.Nov. & S. Fco. & Sid & CNov & SFco \\
\hline MAE(00) & 2.72 & 3.84 & 3.47 & 2.33 & 2.12 & 2.3 \\
MAE(12) & 4.26 & 4.07 & 6.63 & 3.58 & 4.52 & 3.17 \\
Bias(00) & 0.38 & -3.84 & -3.47 & 0.94 & -1.76 & -0.41 \\
Bias(12) & -4.19 & -4.07 & -6.63 & -3.52 & -4.52 & -3.17 \\
\hline Eta & & V10m & & & & \\
\hline Index & Sid. & C.Nov. & S. Fco. & & & \\
\hline MAE(00) & 2,22 & 2.32 & 2.61 & & & \\
MAE(12) & 3.86 & 2.09 & 4.32 & & & \\
Bias(00) & 1.06 & -1.09 & 0.15 & & & \\
Bias(12) & -3.86 & -2.09 & -3.82 & & & \\
\hline
\end{tabular}

\section{Conclusions}

The CPTEC/AGCM forecasts were able to represent the main characteristics associated with Catarina for short range forecasts $(24 \mathrm{~h})$. The observed wind intensity associated to Catarina over South Atlantic Ocean on the 26, the 27 and the 28 March was well reproduced by the wind field from the first sigma-level of the model. The V10m did not represent the pattern verified in reanalyses. The V10m presented elevated bias over both ocean and continent. Despite of problems in the intensity, the SLP field 24-h forecasts reproduced the Catarina formation and its displacement westward until 
(a)

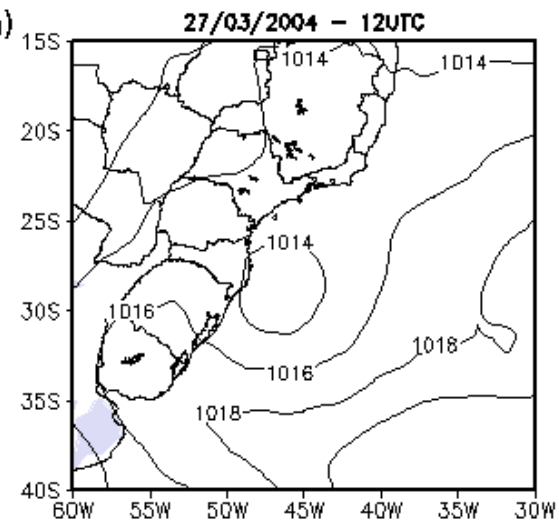

(c)

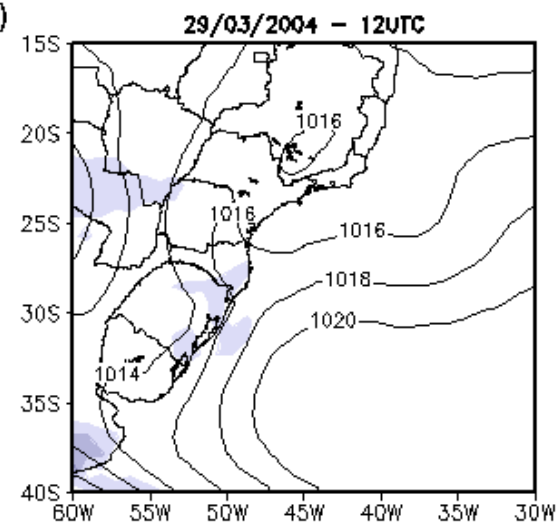

(b)

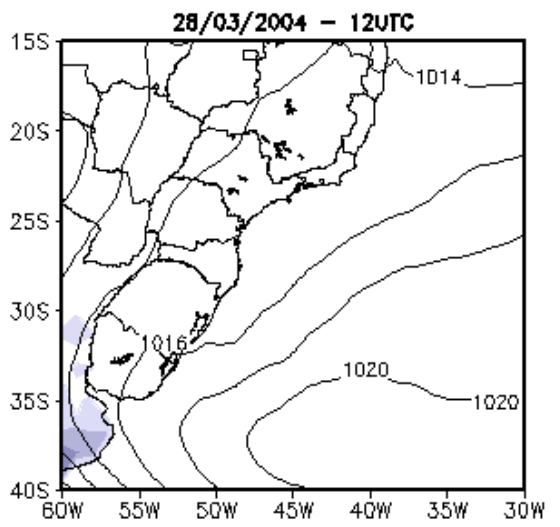

(d)

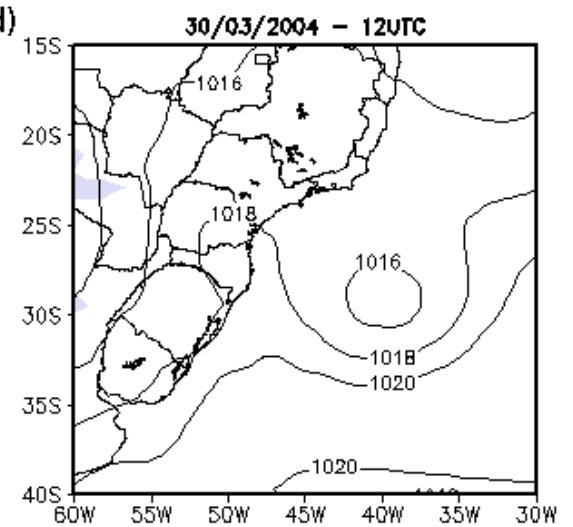

Fig. 5. SLP (solid lines, in hPa) and V10m (shading in $\mathrm{ms}^{-1}$ ) 24-h CPTEC/AGCM forecasts of the valid for: (a) 03/27, (b) 03/28, (c) 03/29 and (d) 03/30 at 12:00 UTC.

hitting the coast. On the $28 \mathrm{March}$, when the center of the pressure was over SC, the CPTEC/AGCM displaced the center eastward, that contributed for weaker wind forecasts over $\mathrm{SC}$ and RS.

The Catarina was an intense meteorological event without precedents in the history of the Brazilian Meteorology. The CPTEC/AGCM presented deficiencies to predict the system intensity, but in short-range forecasts $(24 \mathrm{~h})$ it was possible to predict the formation and atypical trajectory of the system. The knowledge of the way that these extreme events are represented by numerical forecast models may help the forecasters in the process of decision, in order to minimize the damages that this kind of event causes for society.

Acknowledgements. The first author thanks the Conselho Nacional de Desenvolvimento Cientifico e Tecnologico $(\mathrm{CNPq})$ for the research financial support. The authors also thank the Company of Farming Research and Agricultural Extension of Santa Catarina (Epagri) for providing observational data.

Edited by: P. Lagos

Reviewed by: R. Weissmann and K. Takahashi

\section{References}

Aravéquia, J. A., Herdies, D. L., Sapucci, L. F., Andreoli, R. V., Ferreira, S. H. S., Gonalves, L. G. G.: Reanálise Regional 2000-2004 sobre a América do Sul com o Modelo RPSAS/ETA: Descrição do Experimento e dos Produtos Derivados, Boletim da Sociedade Brasileira de Meteorologia, 2008.

Arya, S. P.: Introduction to Micrometeorology, Vol. 79, International Geophysics Series, Academic Press, San Diego, 2 edn., 2001.

Black, T. L.: The new NMC Mesoscale Eta Model: Description and Forecast examples., Weather Forecast., 9, 256-278, 1994.

Bonatti, J. P.: Modelo de Circulacao Geral Atmosferico do CPTEC., in: Climanalise Especial de 10 anos, Chap. 26, CPTEC/INPE, Cachoeira Paulista, SP, 198-202, 1996.

Bonatti, J. P., Rao, V. B., and Silva Dias, P. L.: On the westward propagation of Catarina storm, in: International Conference on Southern Hemisphere Meteorology and Oceanography (ICSHMO), 8, 1659-1675, INPE, Foz do Iguaçu, Brazil, 2006.

Davies, R.: Documentation of the solar radiation parameterization in the GLAS climate model., Tech. Memo. 83961, NASA, 57 pp., 1982.

Grell, G. A.: Semi-prognostic tests of cumulus parameterization schemes in the middle latitudes, Ph.D. thesis, University of Miami, Coral Gables, Florida, 225 pp., 1988. 
Harshvardhan, Davies, R., Randall, D., and Corsetti, T.: A fast radiation parameterization for atmospheric circulation models, J. Geophys. Res., 92, 1009-1015, 1987.

Jolliffe, I. T. and Stephenson, D. B., eds.: Forecast Verification: A practitioner's guide in Atmospheric Science, Wiley, Chichester, Inglaterra, 2003.

Kinter III, J. L., DeWitt, D., Dirmeyer, P. A., Fennessy, M. J., Kirtman, B. P., Marx, L., Schneider, E. K., Shukla, J., and Straus, D. M.: The COLA atmosphere-biosphere general circulation model, Vol. 1, Formulation, COLA Report 51, COLA Staff, 49 pp., 1997.

Lacis, A. A. and Hansen, J.: A Parameterization for the Absorption of Solar Radiation in the Earth's Atmosphere, J. Atmos. Sci., 31, 118-133, 1974.

Mellor, G. L. and Yamada, T.: Development of a turbulence closure model for geophysical fluid problems, Rev. Geophys. Space Phys., 20, 851-875, 1982.

NMC, D. D.: Documentation of the research version of the NMC Medium Range Forecast Model, Tech. rep., NMC, available from NMC Development Division, 1988.
Pezza, A. B. and Simmonds, I.: The first South Atlantic hurricane: Unprecedented blocking, low shear and climate change, Geophys. Res. Lett., 32(L15712), 1-5, 2005.

Sato, N., Sellers, P. J., Randall, D. A., Schneider, E. K., Shukla, J., J. L. Kinter, I., Hou, Y.-T., and Albertazzi, E.: Implementing the simple biosphere model in a general circulation model: Methodologies and results, Contractor Report 185509, NASA, 76 pp., 1989.

Team, M. O. S.: Ocean Surface Winds Derived from the SeaWinds Scatterometer, http://manati.orbit.nesdis.noaa.gov/ quikscat/, 2007.

Tiedtke, M.: The sensitivity of the time-mean large-scale flow to cumulus convection in the ECMWF model, in: Workshop on Convection in Large-Scale Numerical Models, ECMWF, 297-316, 1983.

Wilks, D. S.: Statistical Methods in the Atmospherics Sciences: An Introduction, International Geophysics Series, Vol. 59, Academic Press, San Diego, 465 pp., 1995.

Xue, Y., Sellers, P., Kinter, J., and Shukla, J.: A Simplified Biosphere Model for Global Climate Studies, J. Climate, 4, 345364, 1991. 